\title{
Influence of welding parameters on the geometric and microstructural characteristics of Inconel 625 coatings deposited on ASTM A36 Steel by Plasma Transferred Arc
}

Priscila Pereira Barbosa da Silva ${ }^{1}$, Ivana dos Santos Araújo ${ }^{1}$, Magda Rosângela Santos Vieira ${ }^{1}$, Severino Leopoldino Urtiga Filho ${ }^{1}$

\footnotetext{
${ }^{1}$ Federal University of Pernambuco, Av. Prof. Moraes Rego, 1235, CEP: 50670-901 - University City, Recife, PE, Brazil. e-mail: priscila-pereirab@hotmail.com,nex.ivana@gmail.com, magrsv@ hotmail.com, severino.urtiga@gmail.com
}

\begin{abstract}
This work aims to evaluate the influence of welding parameters, current intensity and deposition speed, on the bead geometry, dilution, morphology and properties of a nickel-based alloy coating. For this, single beads of Inconel 625 alloy were deposited on the substrate of ASTM A36 Steel, by PTA-P process. The samples were sandblasted and polished. The samples were chemically etched by a solution of $92 \mathrm{~mL} \mathrm{HCl,} 3 \mathrm{~mL} \mathrm{HNO}_{3}$ and 5 $\mathrm{mL} \mathrm{H}_{2} \mathrm{SO}_{4}$ for 5 minutes. The geometry of the beads (reinforcement height, bead width, penetration and contact angle) was measured through the digital stereoscope microscope. The microstructures of the cross sections were evaluated by optical microscopy and scanning electron microscopy (SEM), to identify the possible presence of precipitated phases in the ferrite matrix. The chemical composition of these present phases, as well as the diffused iron content from the substrate for the coating, were measured by EDX. The type of the phases precipitated by x-ray diffraction in the top samples of the coating were also evaluated, in $1.5 \mathrm{~mm}$ height of reinforcement. For mechanical property analysis, the microhardness of the coatings was measured by Vickers microhardness test to evaluate their relationship with the iron present in the coatings, which diffused from the substrate. The results confirmed the influence of welding parameters on coating dilution - Current is the parameter of greatest response. The morphologies of the coatings were presented as a $\gamma$ matrix with second phase precipitation composed of $\mathrm{Ni}, \mathrm{Nb}, \mathrm{Cr}$ and $\mathrm{Mo}$. The concentration of these precipitations decreased with increasing dilution. This occurred because of the increased migration of Fe present in the substrate of the coating through the diffusion phenomena, with increasing dilution. The Fe reduced the solubility of $\mathrm{Nb}$ and Mo of the $\gamma$ matrix, causing the decrease of its hardness.
\end{abstract}

Keywords: Plasma Transferred Arc, Inconel 625 Alloy, Bead geometry, Dilution.

\section{INTRODUCTION}

To reduce maintenance downtimes, many manufacturing industries use continuous processes to improve performance of parts working under aggressive conditions [1]. One promising way to mitigate aggressive effects on metal surfaces is to avoid contact with corrosive environments by coating the surface with nobler materials. Superalloys are alloys with high resistance to heat, corrosion, and oxidation, therefore its presence in the aerospace and chemical industries, power plants and in other applications needing high thermal and corrosion resistance components [2,3]. There are three major groups of superalloys, considering the main chemical element in its composition: nickel-based superalloys, cobalt-based superalloys, and iron-based superalloys [4,5].

Ni-based coatings are widely used to improve the oxidation and corrosion resistance as well as the wear performance of less expensive materials such as medium alloy $[6,7,8,9,10,11]$

The Inconel 625 has high corrosion resistance and high ductility, which makes it a potential material for surface modification of oil and gas components [12]. Due to its excellent combination of mechanical properties, weldability and corrosion resistance at high temperatures, over long exposure in aggressive atmosphere, is widely used in aeronautical, aerospace, chemical, petrochemical and marine industries [13,14].

The alloy is hardened by the addition of molybdenum and niobium, which act in the segregation of the 
liquid, in the final solidification reactions, forming the $\gamma^{\prime \prime}$ phase. It also holds a high rate of chromium in its composition, which together with molybdenum, take part in increased resistance to oxidation and corrosion [13].

The microstructures found in the process are composed of an austenitic matrix, with the presence of intermetallic carbides of fine alloys [13]. The generation of carbides $\left(\mathrm{MC}, \mathrm{M}_{23} \mathrm{C}_{6}\right.$ and $\left.\mathrm{M}_{6} \mathrm{C}\right)$ and precipitates $\left(\mathrm{Ni}_{2} \mathrm{Cr}, \mathrm{Mo}\right)$ occur between temperatures $\left(625-925^{\circ} \mathrm{C}\right)$. Dilution of these particulates is noted at $1025^{\circ} \mathrm{C}$.

Several processes are used to produce a weld coat in nickel-based alloys, such as: GMAW, GTAW and blast welding, as well as PTA [1]. The main advantage of the latter is its higher deposition rate, associated with a lower heat consumption $[15,16,17]$. The reduction of the thermal input, on the other hand, implies in the decrease of the dilution. Thus, the chemical composition and coating properties stay closer to the filler metal than the substrate, with only one pass performed, reducing material and operating costs.

The process parameters that interfere the most in the bead geometry and coating dilution are current and deposition speed $[18,19]$. The deposition current has the major influence in the dilution, since small variations in its values cause a considerable increase in the dilution results [1,20]. According to [22,15,18,20], in their studies in commercial alloys, the welding current has a direct proportionality ratio with the dilution, in this way the dilution increases as a consequence of an increase in current. This is due to the thermal input rise, generated by the increase in welding current [15]. The deposition speed has an inverse proportionality relation with the dilution; therefore, the dilution percentage decreases with the increase of the speed. This is due to the low thermal input supplied per unit length to the weld under high speed conditions.

The increase of the dilution due to the welding energy causes the iron to replace elements such as niobium, molybdenum and tungsten, which harden the matrix by solid solution, while decreases the precipitation of secondary phases. [21]

This research's main goal was to evaluate the current and speed parameters of the PTA-P process, on the geometric and metallurgical properties of the Inconel 625 alloy coating, deposited on the substrate of ASTM A36 steel. Thus, weld bead geometry was evaluated (bead width, reinforcement height, penetration, contact angle), dilution degree and microstructure, in relation to welding process parameters (welding current and welding deposition speed).

\section{MATERIALS AND METHODS}

ASTM A36 steel specimens with dimensions of 100x100x7.5mm were coated with Inconel 625 alloy powder, with a particle size ranging from 50-153 $\mu \mathrm{m}$, through the plasma transferred arc process and their compositions are shown in Table 1 , respectively.

Table 1: Ni-based alloy and substrate composition, respectively.

\begin{tabular}{|c|c|c|c|c|c|c|c|c|c|}
\hline \multicolumn{10}{|c|}{ ATOMIZED INCONEL 625 ALLOY } \\
\hline Alloy & $\% \mathrm{Ni}$ & $\% \mathrm{Cr}$ & $\%$ Mo & $\% \mathbf{S i}$ & $\% \mathrm{C}$ & $\% \mathrm{Fe}$ & $\% \mathrm{Nb}$ & $\% \mathrm{Ti}$ & $\%$ Al \\
\hline $\begin{array}{r}\text { Nickel-based } \\
625\end{array}$ & Bal. & 21.5 & 9.0 & 0.40 & $\leq 0.03$ & 1.4 & 3.8 & - & - \\
\hline \multicolumn{10}{|c|}{ SUBSTRATE STEEL } \\
\hline Substrate & $\% \mathrm{C}$ & $\% M n$ & $\% \mathbf{S i}$ & $\% P$ & $\% S$ & $\% \mathrm{Cr}$ & $\% \mathrm{Ni}$ & \%Mo & $\% A l$ \\
\hline ASTM A36 & 0.26 & - & 0.40 & 0.04 & 0.05 & - & - & - & - \\
\hline
\end{tabular}

The coatings were deposited as singles beads. Different process conditions were analyzed in order to evaluate the effect caused by the variation of the welding current and deposition speed values, on the dilution and geometry of the weld beads. Table 2 shows coatings conditions of the samples, that were labelled according to the process parameters variations. The other process parameters were kept constant and are listed in Table 3. 
Table 2: Coatings samples labelled according to the process parameters used.

\begin{tabular}{c|c|c}
\hline SAMPLES & CURRENT (A) & $\begin{array}{c}\text { DEPOSITION SPEED } \\
\text { (mm } / \mathbf{m i n})\end{array}$ \\
\hline C160S8 & 160 & 8 \\
C160S10 & 160 & 10 \\
C180S8 & 180 & 8 \\
C180S10 & 180 & 10 \\
\hline
\end{tabular}

Table 3: PTA deposition parameters

\begin{tabular}{l|l|l}
\hline PARAMETERS & VALUES & UNIT \\
\hline Plasma gas flow & 3 & $1 / \mathrm{mm}$ \\
Flow of shielding gas & 14 & $1 / \mathrm{mm}$ \\
Powder feeding gas & 2 & $1 / \mathrm{mm}$ \\
Torch oscillation frequency & 0.8 & $\mathrm{~Hz}$ \\
Torch-part distance & 12 & $\mathrm{Mm}$ \\
Electrode diameter & 4 & $\mathrm{Mm}$ \\
Electrode sharpening angle & 30 & $\circ$ \\
Powder feed rate & Constant in volume & - \\
Frequency & 0,8 & $\mathrm{~Hz}$ \\
\hline
\end{tabular}

The dilution was calculated by the ratio between the area of the molten substrate (B) and the total area of the bead $(\mathrm{A}+\mathrm{B})$, melted during the process, according to equation (1). The beads' geometries (reinforcement height, penetration depth, cord width and wettability angle) were measured using AxioVision 4.2 digital image processing software. The measured geometries are shown in Figure 1.

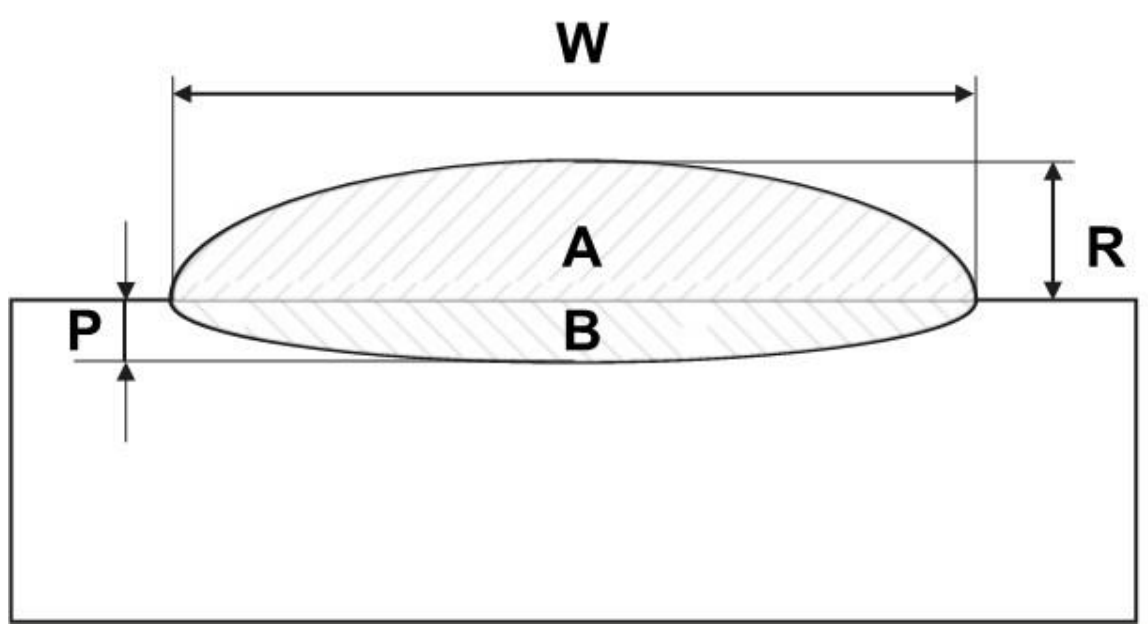

Figure 1: Representation of a coated sample profile. A: molten substrate area after coating process, B: total molten area after coating. 


$$
D(\%)=\frac{B}{A+B}
$$

The microstructures were evaluated using Optical microscopy (OM), Scanning Electron Microscope (SEM) and elemental mapping by Energy Dispersive X-ray Spectroscopy (EDS). The precipitated phase fraction was measured using AxioVision SE64 software.

Specimens were prepared through automatic metallographic polishing, using the automated polishing machine Tegramim-20/Strues. Four steps were followed, beginning with \# 220 sandpaper, going through two diamond suspension polishing routines with $9 \mu \mathrm{m}$ and $3 \mu \mathrm{m}$ grain size, respectively, and lastly undergoing a polishing silica suspension with $0.04 \mu \mathrm{m}$ grain size. Subsequently, it was performed a chemical etch for 5 minutes, using a solution of $92 \mathrm{~mL} \mathrm{HCl,} 3 \mathrm{~mL} \mathrm{HNO}_{3}$ and $5 \mathrm{~mL} \mathrm{H}_{2} \mathrm{SO}_{4}$, at room temperature $\left(23^{\circ} \mathrm{C}\right)$.

$\theta-2 \theta$ X-ray diffraction analysis (XRD) on ground and polished top surface of coatings was carried out using $\mathrm{Cu}-\mathrm{K}_{a}$ radiation, with 2 theta angle from 10 to $120^{\circ}$ and time of exposed channel of $1 \mathrm{~s}$. The stationary parameter used in analysis were, $0,05^{\circ}$ sampling pitch and a $3 \%$ minute speed scan. The results were analyzed using the software HighScore Plus and COD (Crystallography Open Database) was used as a standard of analysis.

Vickers Microhardness test profiles under 100gf were measured on the transverse section to check the uniformity of the single layers and the results were presented as the average of three measurements.

\section{RESULTS AND DISCUSSION}

\subsection{Effect of the welding process parameters in the dilution process}

The effect of the welding process parameters on the dilution process was investigated through the morphological study of the weld bead. Figure 2 shows macrographs of the weld bead region obtained by means of a stereomicroscope for the different conditions studied. The red lines in the figure represent the boundary between the substrate and the deposited metal.

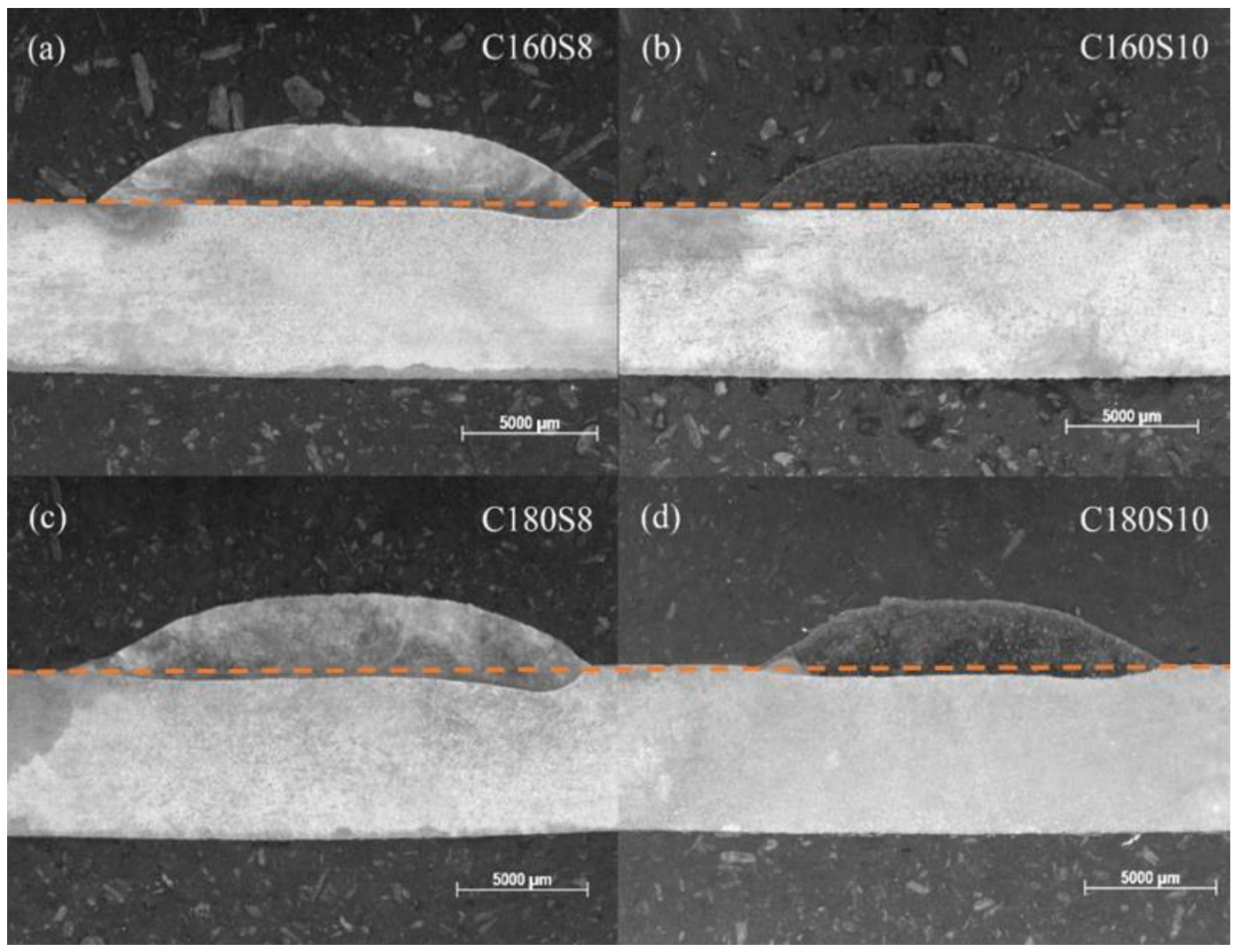

Figure 2: Cross-sectional analysis of the weld beads from different welding parameters: (a)C160S8 (b)C160S10 (c)C180S8 (d)C180S10 
The beads obtained presented good aspects, absence of surface defects as cracks, porosity, bites, lack of fusion and interface defects, indicating that the alloy processing parameters on the steel were adequate. The mean values of height of reinforcement, penetration, weld bead width, contact angle and dilution are reported in the Table 4.

Table 4: Influence of welding parameter in morphology and dilution of weld beads.

\begin{tabular}{c|c|c|c|c|c}
\hline SAMPLE & $\begin{array}{c}\text { HEIGHT OF } \\
\text { REINFORCEMENT } \\
(\mathbf{m m})\end{array}$ & $\begin{array}{c}\text { PENETRATION } \\
(\mathbf{m m})\end{array}$ & $\begin{array}{c}\text { WELD BEAD } \\
\text { WIDTH (mm) }\end{array}$ & $\begin{array}{c}\text { CONTACT } \\
\text { ANGLE ( }{ }^{\circ}\end{array}$ & DILUTION (\%) \\
\hline C160S8 & $2.70 \pm 0.03$ & $0.55 \pm 0.02$ & $18.11 \pm 0.11$ & $37.69 \pm 0.10$ & $5.81 \pm 0.63$ \\
C160S10 & $2.95 \pm 0.03$ & $0.25 \pm 0.02$ & $15.79 \pm 0.43$ & $39.79 \pm 1.63$ & $3.66 \pm 0.79$ \\
C180S8 & $2.52 \pm 0.04$ & $0.85 \pm 0.04$ & $18.33 \pm 0.34$ & $26.27 \pm 1.04$ & $19.46 \pm 1.33$ \\
C180S10 & $2.62 \pm 0.03$ & $0.68 \pm 0.05$ & $16.73 \pm 0.18$ & $28.03 \pm 0.63$ & $16.84 \pm 0.27$ \\
\hline
\end{tabular}

As can be observed in the Table 4, the increase of welding current intensified the dilution process. Comparing the C180S10 and C160S10 samples, it can be observed that the samples with lower current intensity (160A) showed lower dilution percentage (3.66\%). Similar results were obtained by SIVA, MURUGAN, and RAGHUPATHY [15], who identified that the increase of the current implies in the increase of the metal dilution and the width of the weld bead, resulting in increased deposition area.

This increase in the dilution percentage as the welding current rises can be attributed to the intensification of the thermal input. According to TAKANO, QUEIROZ, and D'OLIVEIRA [18], the most impactful parameter of this processes is the intensity of the current, that significantly affects the characteristics of the deposit. They state that the greater the intensity of the process current, the higher the wettability and consequently, so the higher the dilution level, resulting in a lower coating hardness.

According to SIVA, MURUGAN, and RAGHUPATHY [15], the increase in welding current increases the thermal input in the substrate, resulting in a higher deposition. BALASUBRAMANIAN [22] adds that when in low currents, the heat generation is smaller and most of it is used to melt the powder. Thus, less heat is available to melt the substrate of the material after the consumable meltdown.

SIVA and BALASUBRAMANIAN [15,22] investigated the effect of different welding parameters (current, speed, torch oscillation and powder deposition rate) in the process of coatings obtained by PTA in AISI 1040 and ASTM A105 steel. The researchers also showed the current as being the factor that most influenced the dilution process, which reinforces the results obtained in the present work.

By comparing the samples C180S8 and C180S10, it was seen that in the sample at a lower speed $(8 \mathrm{~mm} / \mathrm{min})$, a more pronounced dilution process $(19.46 \%)$ occurred. This can be explained by the fact that the lower the deposition speed, the higher the thermal input and, so, the greater the dilution. BALASUBRAMANIAN [22] also found the dilution process intensification at lower velocity values, attributing this behavior to the intensification of the energy supplied. Related results were found in SIVA, MURUGAN, and RAGHUPATHY [15], which showed that the increase in deposition speed, in general, leads to a decrease in dilution. According to the author this is attributed to the reduction of the thermal input per unit length of the bead.

There is a relation between the welding parameter and the thermal input that repeats along the analysis of the bead's geometries. A higher speed implies in lower inputs, while higher currents result in higher thermal inputs, as shown in Table 4.

A greater penetration of the coating into the substrate was seen when the welding current value was higher, with the highest penetration value of $0.85 \mathrm{~mm}$, for the sample C180S8. The lowest penetration value was obtained for the sample C160S10, which also presented the lowest value for the weald bead width $(15.79 \mathrm{~mm})$. Although the sample C160S10 showed the highest value for the reinforcement height $(2.95 \mathrm{~mm})$, resulted in the lowest dilution value obtained. The penetration has a direct relation with the increase of the thermal input. This is because the thermal input increases the available energy for the melting of the substrate, resulting in greater penetrations. The conditions of lower penetrations are obtained in condition C160S10.

With the increase of the welding energy, the reinforcement heights decrease. The reinforcement heights were smaller for condition C180S8, which presented greater thermal input. 
The weld bead width also was influenced by the welding energy. The condition C180S8 which presented the highest welding energy, resulted larger cord widths.

According to ANTOSZCZYSZYN [1], very high wetting angles can cause lack of fusion and voids between the cords, therefore smaller angles are preferred. The contact angles, as they are also known, behave inversely to the increase in welding energy. Therefore, the condition C180S8 showed the lowest contact angles.

\subsection{Morphology and composition of the coating}

Figure 3 shows the optical microscopy images of the coatings deposited on different processing conditions. The coatings presented solidification dendritic microstructure, composed of a hypoeutetic structure with Nickel dentrites $\gamma(\mathrm{Ni}, \mathrm{Fe}-\mathrm{FCC})$.

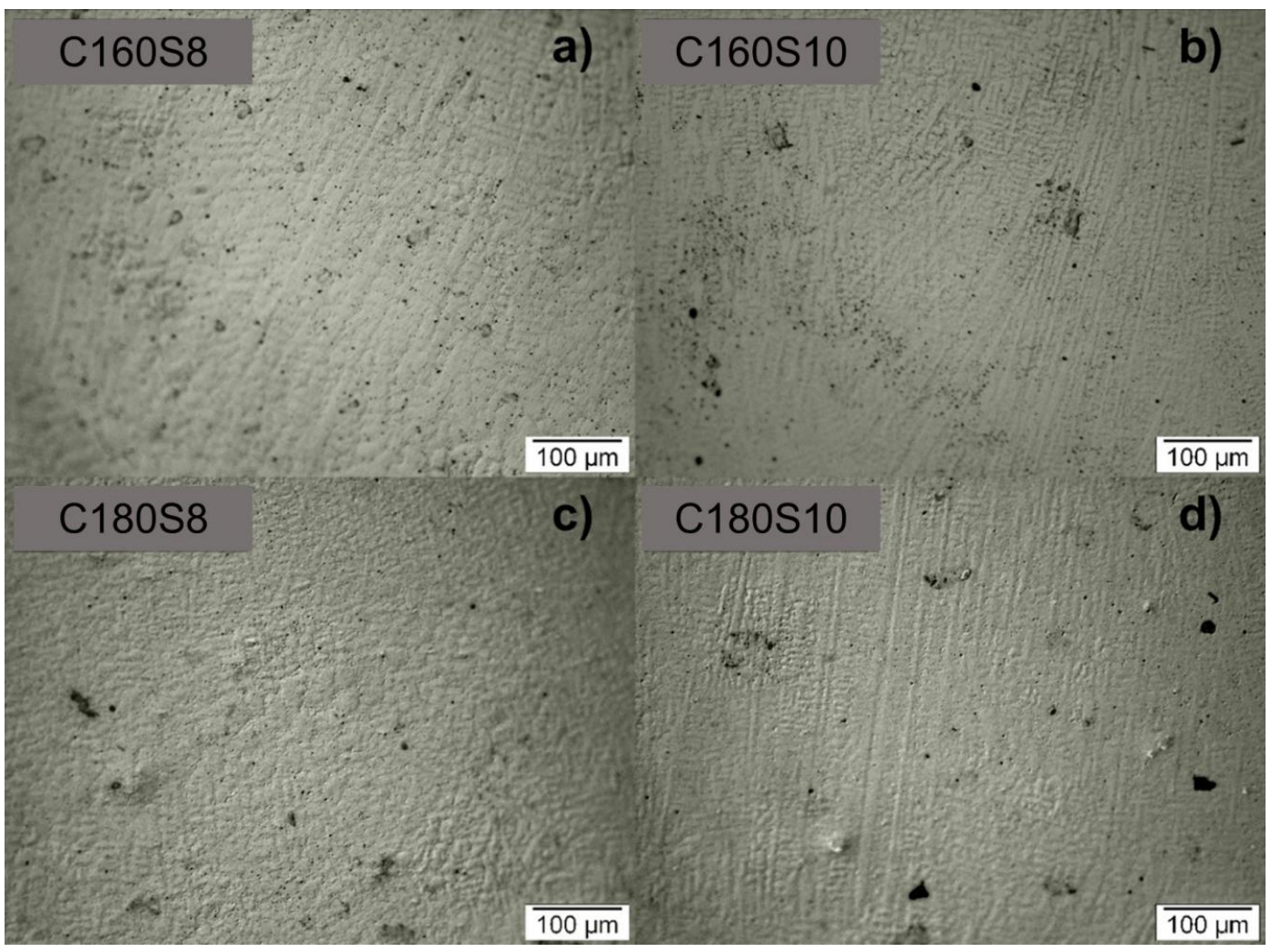

Figure 3: Optical microscopy images of the coatings deposited on different processing conditions

It wasn't found any significant microstructural difference among the dilutions studied. However, it is possible to note that, in the weld metal, the resulting dendrites have different orientations in some regions of the specimen, that is, a different growth direction. According to KOU [23], this happens because the grains nucleate and grow in thermal gradient direction, as the heat flow does not have a continuous direction in the melting pool, those grains that present a more favorable orientation will block the growth of others.

The cross-sectional metallographs, obtained by SEM, under different conditions of welding parameters, are shown in Figure 4. 


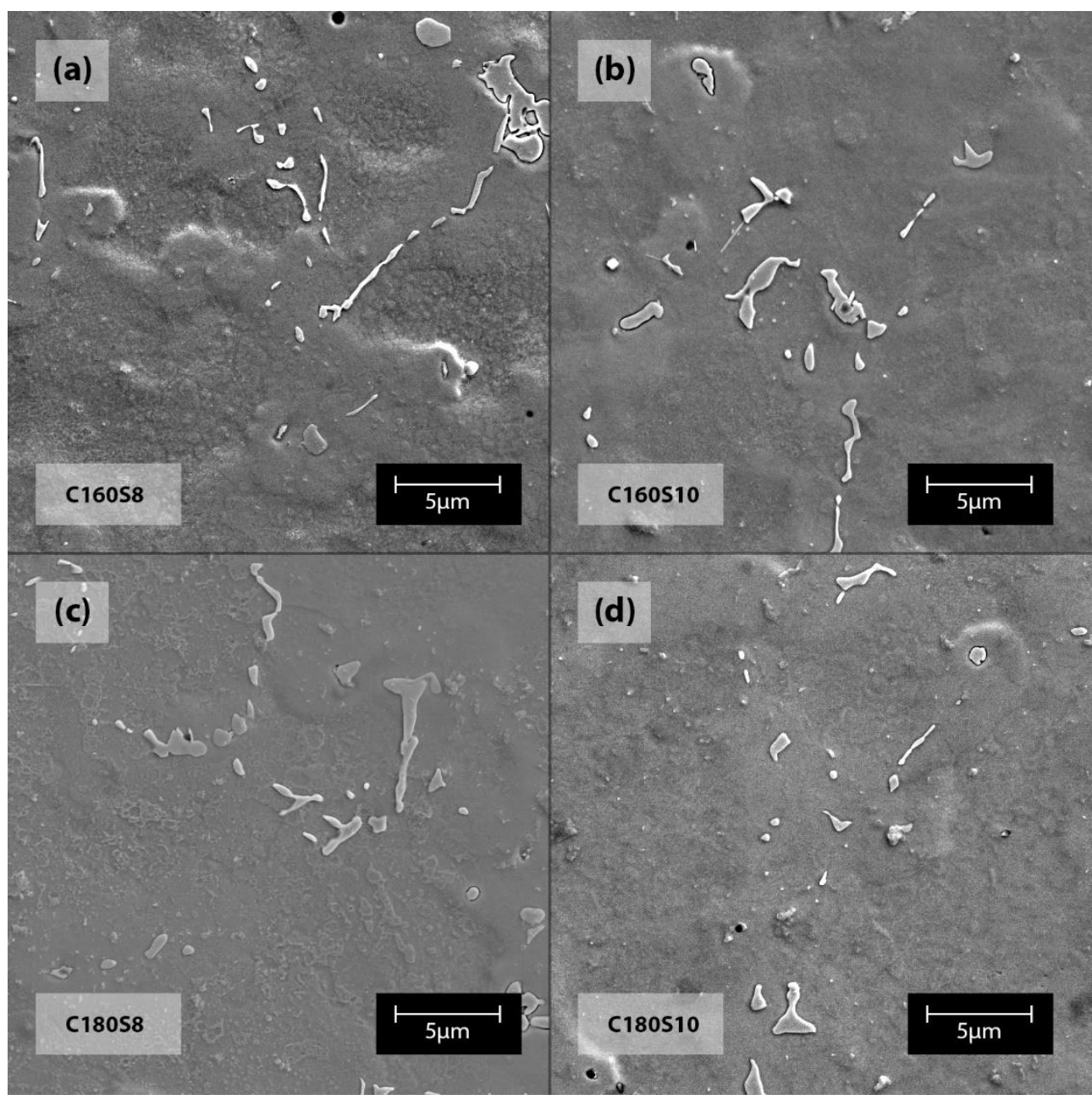

Figure 4: SEM morphology of coatings prepared by PTA deposition: - (a) C160S8; (b) C160S10; (c) C180S8 e (d) C180S10;

SEM results show that, for coatings obtained with higher current values (Figure 4(c) and Figure 4(d)), there was a lower incidence of formed precipitates.

The microstructure of the coatings has similar characteristics, a matrix $\gamma$ with presence of secondary phase as shown in Figure 4. It is possible to observe in Table 5 that the increase in dilution implies in the concentration decrease of the precipitated phase.

Table 5: Correlation between dilution and concentration of precipitated phase.

\begin{tabular}{c|c|c}
\hline SAMPLES & DILUTION (\%) & \multicolumn{2}{|l}{$\begin{array}{l}\text { CONCENTRATION OF PRECIPITATED } \\
\text { PHASE (\%) }\end{array}$} \\
\hline C160S8 & 5,81 & 4.22 \\
C160S10 & 3,66 & 4.32 \\
C180S8 & 19,46 & 1.19 \\
C180S10 & 16,84 & 3.52 \\
\hline
\end{tabular}


Table 6: Elemental chemical compositions obtained in the EDS test of the coatings.

\begin{tabular}{l|c|c|c|c|c|c}
\hline \multirow{2}{*}{ SAMPLES } & DILUTION (\%) & \multicolumn{2}{|l}{ ELEMENTS } \\
\hline & & $\mathrm{Fe}$ & $\mathrm{Ni}$ & $\mathrm{Cr}$ & $\mathrm{Nb}$ & $\mathrm{Mo}$ \\
\cline { 2 - 7 } C160S10 & 3.66 & 6.82 & 63.93 & 23.43 & 3.29 & 7.68 \\
C160S8 & 5.81 & 11.78 & 62.32 & 22.94 & 2.93 & 7.41 \\
C180S10 & 16.84 & 26.03 & 53.63 & 20.47 & 2.52 & 6.43 \\
C180S8 & 19.46 & 28.83 & 53.36 & 20.3 & 2.47 & 6.14 \\
\hline
\end{tabular}

\section{As shown in}

Table 6, the Fe percentage shown in the coating is closely related to the dilution process. It is noted that the plain concentrations of iron in the coatings vary with their percentages of dilution, this is due to the migration of iron from the substrate to the coating by the diffusion process. According to BANOVIC, DUPONT, and MARDER [24] this migration has the intensity increased with increasing dilution.

In the case of $\mathrm{Ni}, \mathrm{Cr}, \mathrm{Nb}$ and $\mathrm{Mo}$, the increase in dilution causes a decrease in the content of these elements. with the increase of the dilution, increases the participation of the iron in the welding metal and with this occurs the reduction of the solubility of elements, like niobium and the molybdenum. These elements migrate naturally into the interdentritic liquid during the welding metal solidification process.

Chemical mapping analyzes by EDS were fulfilled in the samples, aiming to identify the elements present in the precipitates. Figure 5 presents the result of the analysis performed on sample C160S10, which corresponds to the highest concentration of precipitates. Similar results were obtained for the other samples.
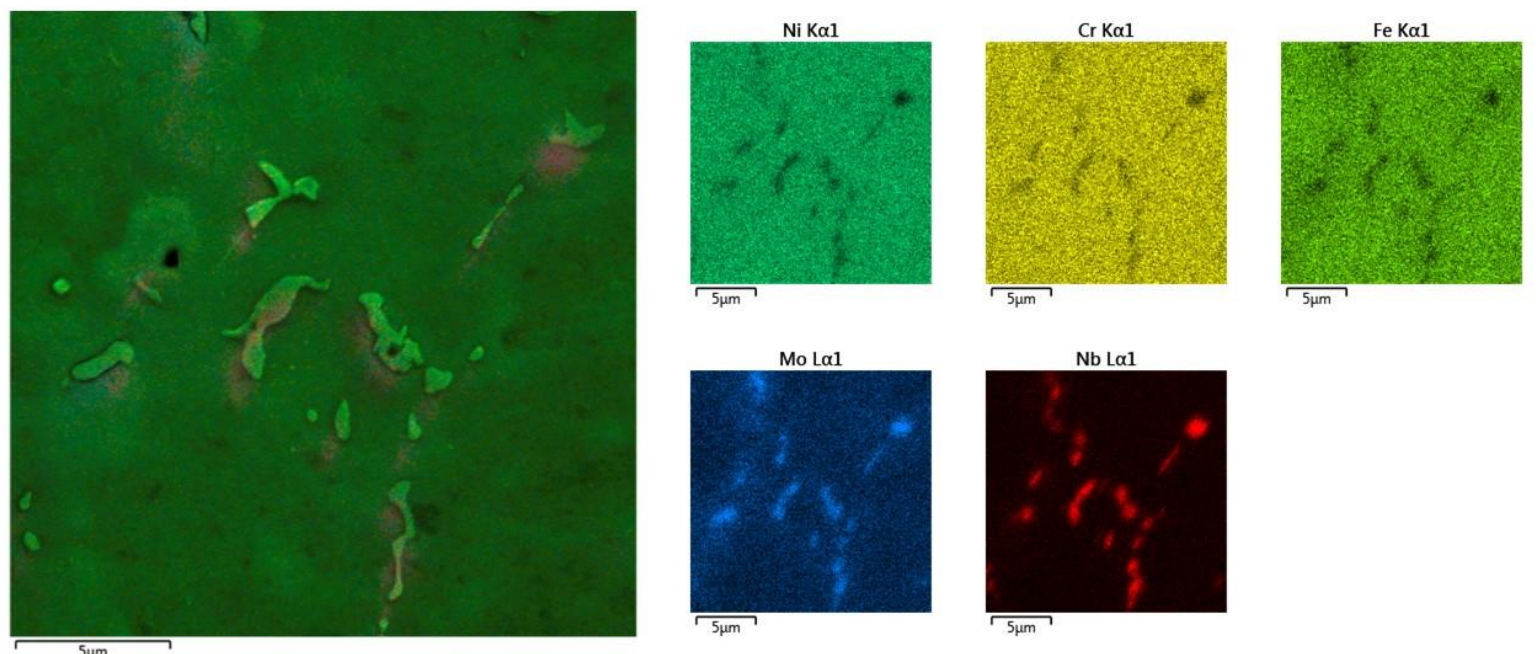

Figure 5: Precipitation analysis of the sample C160S10 by Elemental mapping of EDS.

The composition of the matrix ( $\gamma$-phase) presented the elements $\mathrm{Ni}, \mathrm{Cr}, \mathrm{Fe}, \mathrm{Mo}$, and $\mathrm{Nb}$. The elements $\mathrm{Ni}, \mathrm{Cr}$ and $\mathrm{Mo}$ are the main constituents of Inconel 625. The precipitation regions show an intense presence of Mo and $\mathrm{Nb}$ elements, which can be seen through a remarkable blue and red coloration observed, respectively, in the mapping of these elements. This is due to Fe diffusion from the substrate to the welding metal, causing the solubility decrease of elements $\mathrm{Mo}$ and $\mathrm{Nb}$. Related results were obtained by BANOVIC, DUPONT, and MARDER [24]. 


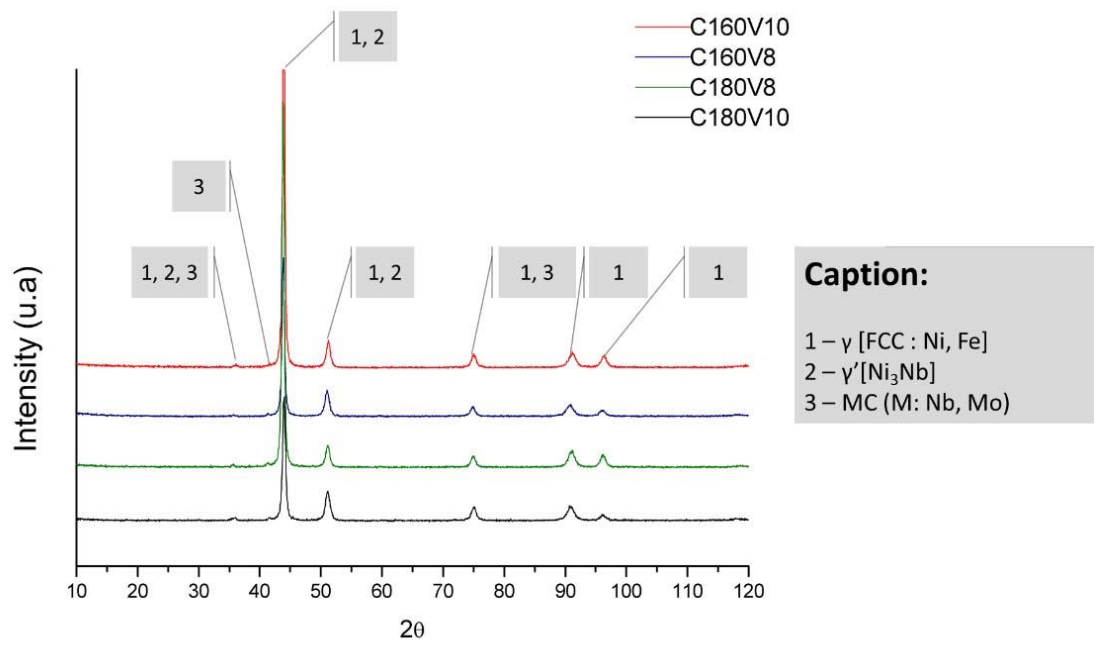

Figure 6: XRD diffractogram of the coatings obtained by PTA.

From the $\mathrm{x}$-ray analysis Figure 6, it was possible to confirm the formation of $\gamma$ (Ni, Fe-FCC), $\mathrm{Ni}_{3} \mathrm{Nb}_{\text {as }} \gamma^{\prime}$ phase and carbides of Niobium and Molybdenum were found, for all deposition conditions. Similar results were expected, since the EDX analysis confirmed the presence of high niobium content in the precipitate ( $\gamma^{\prime}$ phase). The results were consistent with the results found in the study of ANTOSZCZYSZYN [1].

\subsection{Microhardness Test}

Figure 7 shows the results of the hardness test performed on the coatings obtained by different welding parameters. In general, it is possible to note a tendency towards lower hardness values in the coatings with higher dilution values.

As can be seen, samples that were produced in higher currents (C180S8 and C180S10) had lower microhardness values. Comparing the microhardness for these two samples, it was shown that the sample C180S8, obtained from a lower speed $(8 \mathrm{~mm} / \mathrm{min})$, showed the lowest values. This occurs due to the substitution of the matrix alloying elements by $\mathrm{Fe}$, which migrates from the substrate to the welding metal. In this way, the solubility of elements such as $\mathrm{Nb}$ - responsible for the solid solution hardening of the matrix - is reduced, resulting in a secondary phase precipitation decrease [21]. The microhardness results agree with the other results previously presented.

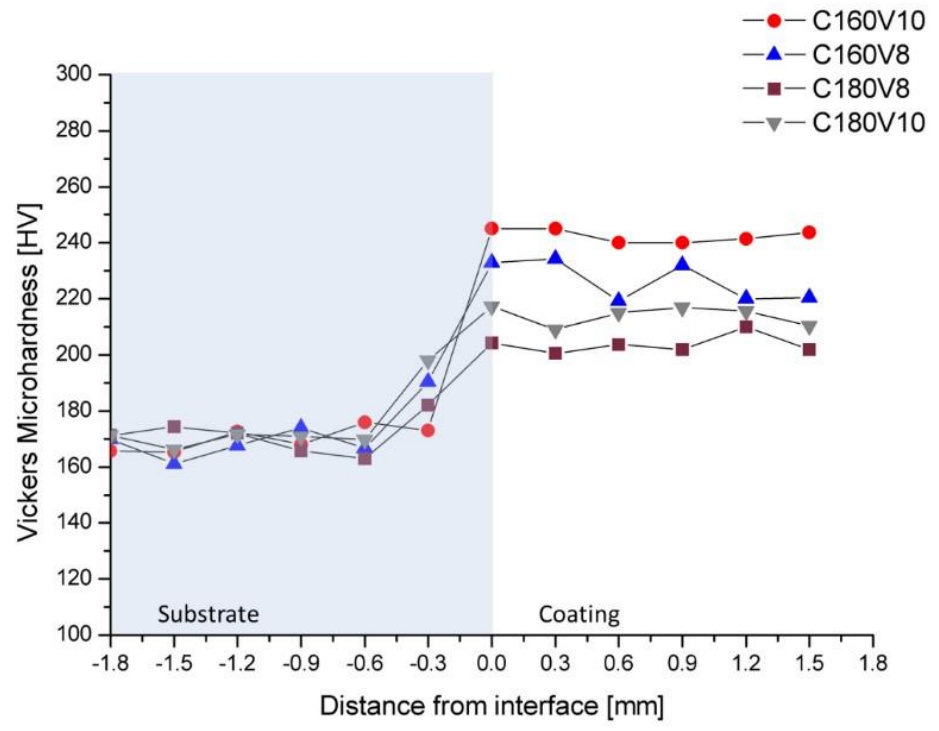

Figure 7: Effect of welding parameters in microhardness of PTA coatings 


\section{CONCLUSIONS}

This work evaluated the impact of the dilution on coatings based on nickel superalloy, Inconel 625, deposited by plasma with transferred arc (PTA-P). Single beads were deposited on ASTM A 36 steel, with different parameters of welding current (180 and 60A) and deposition speed ( 8 and $10 \mathrm{~mm} / \mathrm{min}$ ).

The main contributions on the topic were listed below:

The results confirmed the influence of coating dilution and welding parameters on weld beads geometry. The characteristics of the beads and the percentage of dilution varied according to the welding energy applied to the process. The welding energy increased alongside welding current and decreased as the deposition speed increases. Both penetration, bead width and dilution increased with increasing process welding energy, while the contact angle and the height of reinforcement decrease with the increase of this energy.

Coatings morphologies were presented as a $\gamma$ matrix with second phase $\gamma^{\prime}$ precipitation composed $\mathrm{Ni}_{3} \mathrm{Nb}$. The beads morphology was constituted by a gamma matrix, composed of a substitutional solution between the nickel and the iron present in the addition metal and the steel respectively. The $\gamma$ 'phase is $\mathrm{Ni}_{3} \mathrm{Nb}_{\text {precipitated }}$ throughout the matrix.

These precipitates concentration decreases as the dilution increases. This occurred due to the increase of Fe migration, present in the substrate of the coating, through the diffusion phenomenon. Fe caused a reduction in the element's solubility, the same as $\mathrm{Nb}$ and Mo, which are solid solution hardeners of the matrix. Due to that phenomenon, the matrix had its hardness reduced.

\section{ACKNOWLEDGMENTS}

The authors thank UFPE (Universidade Federal de Pernambuco), CAPES (Coordenação de Aperfeiçoamento de Pessoal do Ensino Superior), CNPq (Conselho Nacional de Desenvolvimento Científico e Tecnológico), COMPOLAB/LBC (Laboratório de Biocorrosão e Corrosão), Petrobras and FINEP (Financiadora de Estudos e Projetos) for the financial and structural support for this work.

\section{BIBLIOGRAPHY}

[1] ANTOSZCZYSZYN, T. J., "Revestimentos de Ligas de níquel Inconel 625 por Plasma com arco transferido (PTA) sobre aços API 5L X70 e AISI 316 L”, Dissertação de mestrado, Universidade Federal do Paraná, Curitiba, 2014

[2] FESHARAKI, M. N, SHOJA-RAZAVI, R., MANSOURI, H. A., et al., "Evaluation of the hot corrosion behavior of Inconel 625 coatings on the Inconel 738 substrate by laser and TIG cladding techniques", Optics and Laser Technology, 2018.

[3] GLAGE, A., "Nickel-based superalloys and their application in the aircraft industry", In: UNIVERSITA' DEGLI STUDI DI TRENTO, 2007.

[4] DAVIS, J. R., “ASM specialty handbook: nickel, cobalt, and their alloys”, ASM International, 2000.

[5] SPECIAL METALS CORPORATION, “Inconel Alloy 625”, Special Metals, v. 63, Jan 2006.

[6] ZHANG, D., HARRIS, S. J., MCCARTNEY, D. G., "Microstructure formation and corrosion behaviour in HVOF-sprayed Inconel 625 coatings", Materials Science and Engineering A-structural Materials Properties Microstructure and Processing, v. 344, n. 1, pp. 45-56, 2003.

[7] AL-FADHLI, H. Y., STOKES, J., HASHMI, M.S.J., et al, "The erosion-corrosion behavior of high velocity oxy-fuel (HVOF) thermally sprayed inconel-625 coating on different metallic surface", Surface and Coating, v. 200, pp. 5782 - 5788, 2006.

[8] BOLELLI, G., LUSVARGHI, L., GIOVANARDI, R., “A comparison between the corrosion resistances of some HVOF-sprayed metal alloy coatings", Surface and Coatings Technology, v. 202, n. 19, pp. 4793-4809, 2008.

[9] WALSH, D.A., LI, L.E., BAKARE, M. S., et al., "Visualisation of the local electrochemical activity of thermal sprayed anti-corrosion coatings using scanning electrochemical microscopy", Electrochimica Acta, v. 54, n. 20, pp. 4647-4654, 2009.

[10] POZA, P., MÚNEZ, C.J., GARRIDO-MANEIRO, M.A., et al., "Mechanical properties of Inconel 625 cold-sprayed coatings after laser remelting. Depth sensing indentation analysis", Surface \& Coatings Technology, v. 243, n. 243, pp. 51-57, 2014. 
[11] LIU, R., WANG, Z., SPARKS, T., et al., "Aerospace applications of laser additive manufacturing”, In: Woodhead Publishing Series in Electronic and Optical Materials, Rolla, pp. 351-371, Sep 2017.

[12] ABIOYE, T. E., MCCARTNEY, D. G., CLARE, A. T. "Laser cladding of Inconel 625 wire for corrosion protection”, In: Journal of Materials Processing Technology, v. 217, n. 217, pp. 232-240, 2015.

[13] SUKUMARAN, A., GUPTA, R. K., KUMAR, V. A., "Effect of Heat Treatment Parameters on the Microstructure and Properties of Inconel-625 Superalloy", Journal of Materials Engineering and Performance, v. 26, n. 7, pp. 3048-3057, 2017.

[14] VERDI, D., GARRIDO, M.A., MÚNEZ, C.J., et al., "Mechanical properties of Inconel 625 laser cladded coatings: Depth sensing indentation analysis", Materials Science and Engineering A-structural Materials Properties Microstructure and Processing, v. 598, pp. 15-21, 2014.

[15] SIVA, K., MURUGAN, N., RAGHUPATHY, V. P., "Modelling, analysis and optimisation of weld bead parameters of nickel based overlay deposited by plasma transferred arc surfacing", In: Archives of materials science and engineering, v. 1, pp. 174-182, 2009.

[16] SILVA, R. H. G. E., "Inovações em equipamentos e em parametrização no processo de revestimento por plasma-pó (PTA-P)”, Tese de D.Sc., Universidade Federal de Santa Catarina, Florianópolis, 2010.

[17] MARCONI, M., MARCONI, B., "Powder Plasma Arc Welding on Thick Walled Pipes", International Institute of Welding, v. 11, pp. 16, 2005.

[18] TAKANO, E. H., QUEIROZ, D. D., D'OLIVEIRA, A. S. C. M., "Evaluation of processing parameters on PTA hardfacing surfaces", In: Welding International, v. 24, n. 3, pp. 241-248, 2010.

[19] JOURNAL, I., DASGUPTA, E. B., MUKHERJEE, S., "Optimisation of Weld Bead Parameters of Nickel Based Overlay Deposited By Plasma Transferred Arc Surfacing”, 2014.

[20] MARIMUTHU, K., MURUGAN, N., "Prediction and optimisation of weld bead geometry of plasma transferred arc hardfaced valve seat rings", Maney for the institute of Materials, Minerals and Mining, Coimbatore, v. 19, n. 2, pp. 143-149, May 2003.

[21] AGUIAR, M. W., "Revestimento por soldagem MIG/MAG empregando ligas de níquel para aplicação em componentes do setor petróleo e gás”, Tese de D.Sc., Universidade Federal do Ceará, Fortaleza, 2010.

[22] BALASUBRAMANIAN, V., "Application of response surface methodology to prediction of dilution in plasma transferred arc hardfacing of stainless steel on carbon steel”, Journal of Iron and Steel research, International, v. 16, n. 1, pp. 44-53, 2009.

[23] KOU, S., Welding Metallurgy, 2 ed., New Jersey, Wiley-Interscience, 2003.

[24] BANOVIC, S. W., DUPONT, J. N., MARDER, A. R., "Dilution and microsegregation in dissimilar metal welds between super austenitic stainless steel and nickel base alloys", Science and Technology of Welding and Joining, v. 7, n. 6, pp. 374-383, 2002.

[25] SILVA, R. H. G. E., DUTRA, J. C., "Processo PTA-P - Uma revisão da Literatura como base para inovações. Parte 1 de 2: Elementos Construtivos", Revista Soldagem \& Inspeção, São Paulo, v. 17, n. 1, pp. 7685, Jan/Feb 2012.

\section{ORCID}

Priscila Pereira Barbosa da Silva Ivana dos Santos Araújo Magda Rosângela Santos Vieira Severino Leopoldino Urtiga Filho

https://orcid.org/0000-0002-7428-1429

https://orcid.org/0000-0002-9198-6105

https://orcid.org/0000-0003-1910-4072 https://orcid.org/0000-0003-4657-1602 